ISSN: 0514-7336

DOI: http://dx.doi.org/10.14201/zephyrus2013727393

\title{
LA IMPLANTACIÓN NEOLÍTICA EN LA BAHÍA DE GIJÓN DESDE LAS POSTRIMERÍAS DEL V MILENIO A. C.: ENFOQUE ARQUEOLÓGICO Y PALEOAMBIENTAL Y NOTAS SOBRE LA MONUMENTALIDAD MEGALÍTICA
}

\section{Neolithic implantation in the Bay of Gijón (Asturias) from the late fith millennium BC: an archaeological and paleoenvironmental approach and notes about megalithic monuments}

\author{
Miguel Ángel DE Blas CorTina \\ Dpto. de Historia. Facultad de Filosofía y Letras. Universidad de Oviedo. Correo-e: deblas@uniovi.es
}

Recepción: 20/07/2012; Revisión: 2/10/2012; Aceptación: 19/11/2012

BIBLID [0514-7336 (2013) LXXII, enero-junio; 73-93]

RESUMEN: Los primeros indicios antropogénicos en la bahía de Gijón pudieran delatar una precoz actividad pastoril c. $7300 \mathrm{cal} \mathrm{BP,} \mathrm{mientras} \mathrm{que} \mathrm{la} \mathrm{agricultura} \mathrm{de} \mathrm{cereales} \mathrm{se} \mathrm{documenta} \mathrm{en} \mathrm{4700-4500} \mathrm{cal} \mathrm{BC} \mathrm{en}$ Monte Areo, donde poco después serían erigidos los túmulos más antiguos, en paralelo con la consolidación de la economía agropecuaria. Hacia 5000 cal BC el mar alcanzó un nivel cercano al actual, sumergiendo una franja litoral en la que hubo de transcurrir parte de la vida mesolítica. Los estudios arqueobotánicos descubren durante ese tiempo la alta potencialidad alimenticia del medio vegetal. El litoral aportaba además cuantiosos recursos piscícolas y malacológicos. Todo ello justifica la concentración humana y la permanencia de gentes cuyo vínculo con un ámbito rico y reducido las abocaría a su explotación intensiva, generando condiciones materiales que favorecerían el arraigo de la economía campesina. La erección de megalitos a partir de 4000 a. C. denuncia tanto la tensión territorial derivada del conflicto entre el modelo ancestral de caza/recolección y las formas paleocampesinas como la presumible ruptura de una dominante horizontalidad social. Al mismo tiempo, del número de monumentos y de ciertos rasgos de los mismos, se infiere un hábitat disperso, organizado en grupos compuestos por pocos individuos, circunstancia extrapolable a buena parte del territorio cantábrico.

Palabras clave: Mesolítico. Territorio cantábrico. Morfología costera. Horizonte marino. Recursos vegetales. Agricultura. Túmulos.

ABSTRACT: The earliest signs of anthropogenic involvement in the Bay of Gijón may reveal early pastoralism around $7300 \mathrm{cal} \mathrm{BP}$, whereas the farming of cereals is documented in the same area (Mount Areo) around $4700-4500 \mathrm{cal} \mathrm{BC}$. From $4300 \mathrm{cal} \mathrm{BC}$ was to see the raising of the most ancient barrows in parallel to the consolidation of the livestock breeding economy. Around $5000 \mathrm{cal} \mathrm{BC}$, the sea level rose to close to that of the present day, submerging a wide coastal strip in which an essential part of Mesolithic life took place. Archaeobotanical studies have discovered the high food potential of the plant environment. The coastal area also provided substantial and varied resources of fish and molluscs. The suitability of the territory justifies the gathering of humans there and the permanence of people whose close links to such a rich yet 
reduced environment was to lead to its intensive exploitation, thereby possibly creating the material conditions that were to favour the establishment of the peasant-farmer economy as a solution. The erection of megaliths from $4000 \mathrm{BC}$ onwards reflect both the territorial tension and the presumed breakdown of a dominant social horizontality. Furthermore, from the number of monuments and certain of their features, a scattered habitat may be inferred organised in groups composed of few individuals, a circumstance that may be extrapolated to much of the territory bathed by the Bay of Biscay.

Key words: Mesolithic. Cantabrian Territory. Coastal morphology. Sea level. Plant resources. Agriculture. Barrows.

\section{Introducción ${ }^{1}$}

En el territorio litoral que consideramos -abarcando un frente de no más de $20 \mathrm{~km}$ - se ubican los conjuntos de túmulos y megalitos de Monte Areo, Monte Deva y Rioseco, a los que cabría añadir los muy cercanos de la Llaguna de Niévares, en el límite de los concejos de Gijón y Villaviciosa, todos ellos erigidos en áreas elevadas y siempre con el océano, al norte, como horizonte. Suman los conjuntos señalados en torno al medio centenar de monumentos. No es esta concentración un rasgo generalizado en la organización del espacio monumental neolítico en la fachada marítima del Cantábrico central, salvando la excepción notable del potente foco de la Sierra Plana de La Borbolla, en Llanes, agrupamiento de túmulos relacionado con el prestigio transmilenario de Peña Tú, una singular roca sagrada impuesta como eje vital en la prehistoria de la Marina oriental de Asturias (de Blas, 2010).

Cabe reconocer en la progresiva erección en torno a la bahía gijonesa de las aludidas concentraciones de dólmenes y túmulos de estructura diversa la consecuencia de causas bien concretas: ineludiblemente la realidad de una población de raigambre mesolítica de ciertas dimensiones, de grupos humanos asentados en la comarca de Gijón al socaire de las condiciones idóneas ofrecidas por un sector costero en el que confluían considerables opciones de pesca, marisqueo, recolección vegetal y caza.

\footnotetext{
${ }^{1}$ Gratiarum nota: en la preparación infográfica de las ilustraciones pude contar con la grata ayuda de los arqueólogos Fernando Rodríguez del Cueto y Esperanza Martín.
}

\section{La vaguedad mesolítica y la certeza neolítica en la segunda mitad del $\mathrm{V}$ milenio a. C.: morfología del espacio litoral, recursos de subsistencia y otras consideraciones paleoambientales}

Hace ya tiempo que fue observada en el norte peninsular la expansión forestal en los milenios comprendidos entre 8000 y 3000 BP, tiempo de neto dominio del bosque, con lógicos intervalos y pequeños retrocesos a los que no sería ajena la acción antrópica. En bajas altitudes y áreas litorales imperaban las especies caducifolias características del ámbito euro-siberiano como Corylus, Ulmus, Tilia, y otras (Ramil et al., 1998).

En el centro de Asturias, la proximidad de la ría de Villaviciosa a la bahía gijonesa permite que la información arqueobotánica obtenida en los depósitos sedimentarios de aquella pueda orientarnos sobre el paisaje vegetal en el segmento costero que consideramos. La secuencia polínica establecida en la aludida desembocadura revela en $6180 \pm 40$ вP (Beta-154350), delimitando el intervalo 5250-5010 cal BC -95\%; curva de calibración CALPAL07 HULU, de la Universidad de Colonia- que, a fines del VI milenio y coincidiendo con el "óptimo climático" del Holoceno medio, habían adquirido un considerable protagonismo las formaciones forestales de Quercus y Corylus, presentes además otras especies de hoja caduca, en particular abedules, tilos, olmos, hayas, fresnos, álamos, sauces y alisos; estos dos últimos instalados en fondos de valle de suelos ricos y profundos (García Antón et al., 2006).

Concuerda esta reconstrucción del paisaje forestal con la inferida en el entorno de la propia bahía de Gijón a partir de los estudios polínicos de la turbera de la "Cañada del Reguerón". El pequeño humedal de este nombre localizado en el 
sector sureste de Monte Areo, en un escalón abierto en la vertiente serrana a unos $170 \mathrm{~m}$ de altitud, fue objeto en 2000, por nuestro encargo, de un primer análisis botánico ${ }^{2}$ entre las distintas aportaciones al Plan director para la Promoción de Monte Areo. Debidamente sondeado el humedal años después, pudo ser reconocido en el lapso $8000-5500 \mathrm{cal} \mathrm{BP}$-entre 64 y $117 \mathrm{~cm}$ de profundidad- el alto índice de las especies forestales, cercano al 90\%, predominando Quercus y Alnus; son pues bosques de robles y alisos a expensas del retroceso de los abedulares. Por otra parte, la detección de microesporas de Byssothecium circinans pudiera ser reflejo de condiciones de aridez, o acaso de la subida de la temperatura durante el Holoceno medio. Influyen en esta interpretación la frecuencia de ciertas microalgas (Spyrogira) y la irrupción episódica de Pinus pinaster, rasgos botánicos de los sustratos arenosos inmediatos a áreas

litorales. Pero lo más sugerente del período sería el incremento del porcentaje de Erica y pólenes de herbáceas relacionadas con la actividad humana. Posteriormente, entre $75-80 \mathrm{~cm}$, se registran los primeros cultivos de cereales, acontecimiento simultáneo con algunos indicadores de erosión como la presencia de Glomus y Pseudoschizaea y el incremento de los helechos instalados en áreas aclaradas (López-Merino et al., 2010).

A esta recreación del paisaje botánico deben ser añadidas las particularidades de la morfología y estructura del frente costero, recurriendo a la amplia serie de sondeos practicados entre la Costa da Morte, en Galicia, y la bocana de la ría de Villaviciosa, con análisis sedimentológicos tanto de litofacies como de biofacies apoyadas las respectivas ubicaciones cronológicas en 77 fechas radiocarbónicas (Alonso y Pagés, 2010). De todo ello se concluye que tras la posición del nivel del mar a $40 \mathrm{~m}$ por debajo del horizonte ac-

tual hacia 11200 $\mathrm{BP}$, sucedió un rápido ascenso de las aguas hasta 7500 BP como consecuencia de la deglaciación holocénica. Tan acelerada transgresión hubo de generar el anegamiento hacia 8500 BP de la parte interna del estuario del Navia, circunstancia también apreciada mil años después en el de Villaviciosa. A partir de entonces, seguirían a un tiempo de estabilización varios episodios alternos de subida y bajada del plano oceá-

${ }^{2}$ Rozas Ortiz, V. (2001): "Humedal de la Cañada del Reguerón: estudio biológico y propuesta de valoración”, en de Blas Cortina, M. A.: Plan director para la promoción cultural de Monte Areo. Ayuntamiento de CarreñoUniversidad de Oviedo-Ayuntamiento de Gijón, vol. I, pp. 134-168, documento inédito. nico. Tras 6820 cal BC se habría fijado el mar entre -5/-7 m con respecto a su horizonte actual, nivel mantenido unos 2600 años y coincidente con el "óptimo climático" identificado con nitidez en el Atlántico norte (Fig. 1). Fue este último episodio térmico un 
prolongado ciclo de dominio sedimentario causante de la ampliación de las barreras arenosas en la costa, además de la generación de lagunas litorales de agua dulce y de la formación de turberas. En suma, entre los milenios V y III a. C. - precisamente el tiempo de la aceptación y asimilación del modo de vida neolítico-, la morfología y estructura de la bahía gijonesa no serían demasiado diferentes de las conocidas en tiempos históricos.

Estudios en detalle basados en numerosos sondeos en el suelo del Gijón actual (Flor y Lharti, 2008) confirman que la mayor parte del espesor sedimentario -fases 1 y 2 - ya se habría acumulado con anterioridad al 5000 BP como secuela de la elevación del nivel del mar Cantábrico. La fase 2 cuenta con la fecha $5360 \pm 80$ BP (Gutiérrez Claverol et al., 2000), que en ańos solares se adecua al intervalo 4410-3970 cal BC (p, 95,4\%; CALPAL07 HULU), de lo que se infiere que en la segunda mitad del V milenio la facies estuaria se habría ido sustanciando en dunas de barrera con potencias de hasta $15 \mathrm{~m}$, delimitando llanuras fangosas drenadas por los canales mareales (Fig. 2).

Parece pues bastante firme la idea de que las condiciones naturales en el trascendental $\mathrm{V}$ milenio serían tanto o más propicias que las que habían

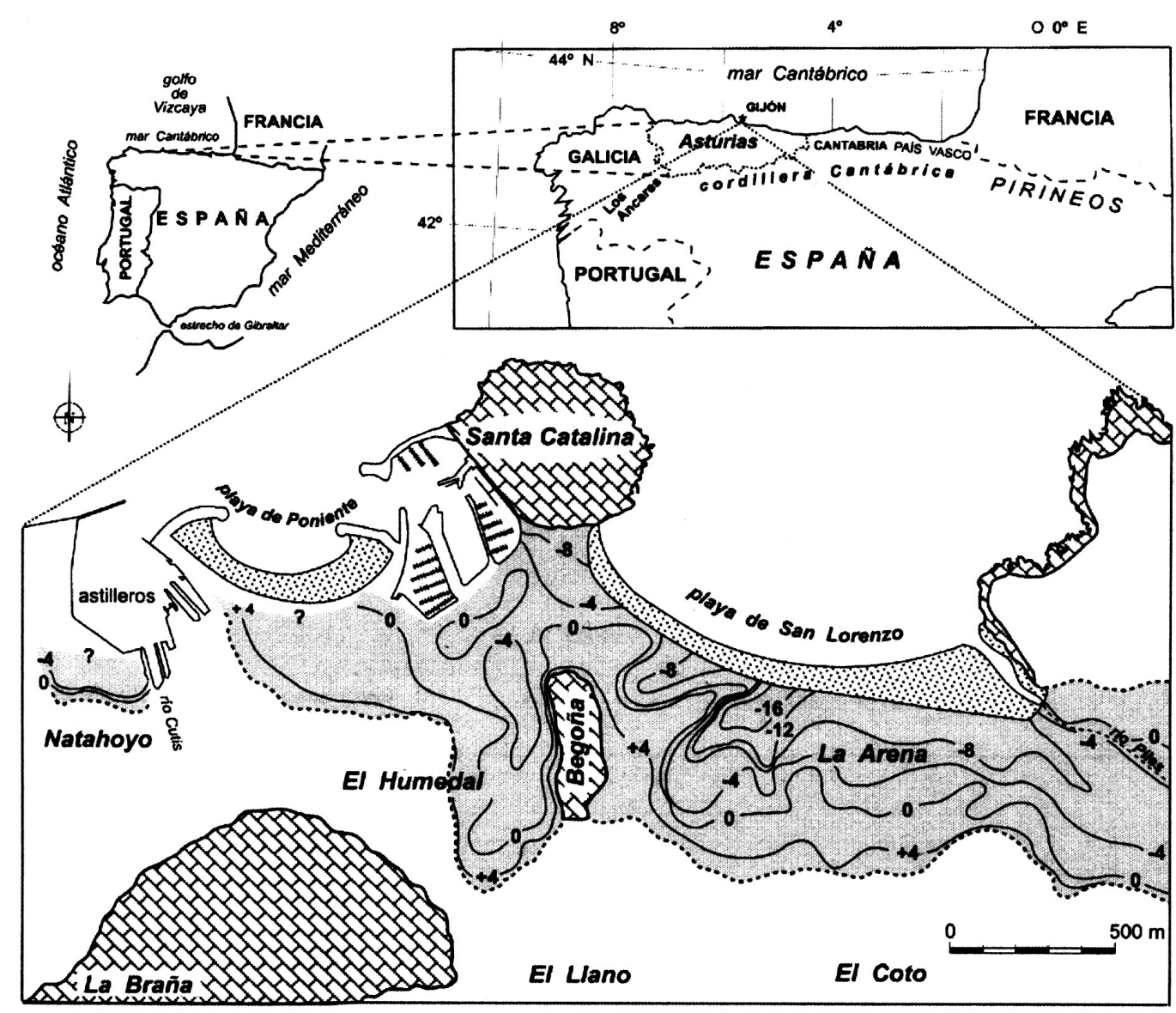
recubrimiento sedimentario costero
de edad holocena playas arenosas activas

calizas, dolomias y margas liásicas (Formación Gijón)

contacto discordante o disconforme

isopacas $(\mathrm{m})$, respecto al " 0 " topográfico

FIG. 2. Paleogeografía de la costa de Gijón antes de $5368 \pm 80$ BP (según Flor y Lharti, 2008). 
permitido la fijación de los modos de subsistencia de las gentes que en taxonomía cultural distinguimos como mesolíticos asturienses, grupos humanos identificados en otras comarcas del litoral central cantábrico merced a los característicos basureros, los "concheros asturienses" de la Asturias oriental, a la postre de magro contenido arqueológico, asociados en aquel medio cárstico a cuevas y abrigos rocosos, accidentes hidrogeológicos apenas existentes en la costa de Gijón.

\subsection{Algunas consideraciones sobre los recursos vegetales silvestres}

Más allá de una genérica y vaga referencia a la explotación de los recursos vegetales, las indagaciones etnobotánicas descubren la extrema potencialidad dietética de una cuantiosa variedad de plantas silvestres hoy ignoradas -son 80.000 las comestibles en todo el mundo, aun cuando el $90 \%$ de los alimentos vegetales básicos proviene en la actualidad de poco más de 20 especie (Tardío et al., 2002: 19)-, bajo la imposición de pautas agrícolas estrictas, determinantes de que en la categoría descalificadora de "malas hierbas" se incluyan tantas especies muy apreciadas tiempo atrás. Esa tendencia reducionista, relativamente reciente aunque ya el Neolítico tuviera un acusado impacto selectivo (Guilaine, 2011: 156-159), hace que también sea ignorado o apenas conocido el valor nutritivo de muchos vegetales bajo el preponderante "mito de la proteína animal" (Couplan y Stiner, 2009: 8 y ss.).

Valorando la rentabilidad de la biomasa atlántica se llegó a calcular entre 20 y 25 las toneladas de rizomas comestibles de potencial producción en un solo kilómetro cuadrado de superficie, riqueza que permitió imaginar un alto grado de especialización en la colecta mesolítica de helechos (Clark, 1978: 14), posibilidad dudosa si se considera el pequeño tamaño de las raíces de las especies comunes en la Europa templada donde, por otra parte, nada parece apuntar a la invención de una agricultura o sistema cuasi-agrícola a partir de las plantas nativas (Rowley-Conwy, 1986: 27). Desde luego, ello no obsta para que sea desatendida la prodigalidad que Clark detallara cuantitativamente: $\operatorname{los} 700 \mathrm{a}$ 1.0001 de bellotas comestibles rentados por cada roble maduro, la tonelada y media de avellanas por ha, los 5.000/10.000 kg de hongos, los $13 / 15 \mathrm{~kg}$ diarios de frutos de zarzamora en temporada, además del recurso extenso a otras muchas plantas comestibles. Las reservas que se suelen plantear al consumo de bellotas por el amargo e indigesto tanino deben ser obviadas ante la opción razonable, y bien contrastada etnográficamente, de su uso alimenticio tras el tostado o cocción que neutralizan la sustancia tóxica (Dimbleby, 1978: 35 y ss.).

Desde luego, hablan de esa potencialidad nutricia los datos polínicos de Monte Areo correspondientes a depósitos de fines del VII milenio, revelando un panorama botánico en el que dominaban los robles -cuyas bellotas aportan almidones, azúcares, proteínas y lípidos- y los abedules -con savia en la que encontrar sacarosa y sales minerales-, además de alisos a los que se suelen asociar hongos comestibles como Mytrophora hybrida o Morchella esculenta (L). Un espectro forestal similar se concluye del registro paleobotánico de la ría de Villaviciosa donde $c .5000 \mathrm{cal} \mathrm{BC}$ es manifiesta la copiosidad de robles y avellanos.

Bastante más discreto, pero sin duda importante, hubo de ser también el cortejo de plantas rústicas comestibles que así mismo testimonian los controles polínicos de Monte Areo y Villaviciosa, con especies de cuyo valor nutritivo, en general alto, anotamos algunas particularidades:

- Polygonum persicaria: verdura silvestre de la que se consumen semillas, hojas y rizoma, aportando aceite esencial y glúcidos.

- Urtica dioica: proteínas (40\% del peso en seco; el doble que la soja), vitaminas A y C más sales minerales.

- Pteridium aquilinum: helecho del que se comen el rizoma, grueso y rico en almidón, y los brotes jóvenes.

- Artemisia: tallos tiernos y brotes jóvenes; aceite esencial.

- Cirsium: cardo, tallos jóvenes, tiernos, dulces; a veces también se consumen las raíces.

- Brassicaceae: como el rábano rústico, berro de invierno: protovitamina $\mathrm{A}$, vitaminas $\mathrm{B}$ y $\mathrm{C}$ y sales minerales.

- Chenopodiaceae: numerosas especies comestibles en la Península Ibérica entre las que se encuentran las 
espinacas silvestres. Se comen las hojas y semillas; vitaminas A, B y C, calcio, fósforo, hierro, proteínas completas, saponinas y ácido oxálico.

- Rumex: acedera, rica en ácidos orgánicos y ácido oxálico.

- Plantago lanceolata: llantén menor: hojas ricas en proteínas, vitamina $\mathrm{C}$ y sales minerales.

- Cichorium: achicoria: verdura silvestre; hojas ricas en provitamina A -15 veces más que el tomate-, vitaminas B y C, potasio, calcio y sales minerales.

Tras este breve apunte gastronómico convendría recordar que el valor nutritivo de las hoy consideradas "malas hierbas" fue vital en épocas de hambruna e incluso cuando no fueron tales las circunstancias imperantes, utilizadas bastantes plantas salvajes como complemento del régimen alimenticio normal en sociedades de seguro desarrollo agrícola. A tal respecto nos ilustran los análisis de los coprolitos y contenido intestinal de los cadáveres de la Edad del Hierro arrojados a los pantanos y turberas de Escandinavia y Gran Bretaña (Holden, 2001). No se debería atribuir a la casualidad la alta proporción de avellanas contenida en los intestinos del individuo conocido como Lindow III, ni tampoco la reiterada presencia de especies silvestres en otros hombres momificados en los pantanos: hasta 59 variedades no cultivadas fueron las identificadas en el aparato digestivo del "hombre de Grauballe" (Helbaek, 1980). Llamativamente, en el estomago e intestinos de Lindow Man I figuraban 10 especies silvestres entre las que señalamos - por su iluminadora presencia en Monte Deva y Villaviciosa- Chenopodium, Rumex y Polygonum (Brothwell, 1986: 92).

Habría que entender, en todo caso, que en sociedades prehistóricas, al igual que en las primitivas subactuales, la convivencia con el hambre fue reiterada, a veces de modo permanente y durante generaciones. En tal realidad, el concepto de dieta inadecuada carece de sentido; las hambres participaban del régimen biológico humano "constituyendo una estructura de la vida cotidiana” (Braudel, 1974: 60).

Pero además, retornando al hinterland de la bahía de Gijón, la producción forestal inducida de los datos paleobotánicos disponibles no podía dejar de tener, en paralelo con su contribución directa al alimento humano, un lógico efecto sobre la población animal. El bosque fue la esencial fuente indirecta del ciclo nutritivo derivado de la caza, a su vez factor esencial en la subsistencia mesolítica. Es razonable que la potencialidad en recursos alimenticios del entorno vegetal de la bahía gijonesa $-\mathrm{y}$ su apuntada conversión parcial en proteínas animales- actuara tanto en el VI como en el V milenio, y aun después, en pro de la estancia humana continuada en aquel territorio, probablemente con una discreta tasa demográfica inicial, estableciendo una favorable relación entre gente, recursos y dieta; tendencia positiva que, a la larga, hubo de acrecentar la entidad del capital humano en el umbral del paulatino paso a la agricultura durante el oscuro trance de adopción por los mesolíticos locales de las formas de vida neolíticas.

\subsection{La potencial explotación de los recursos marinos y la huella de los mesolíticos "asturienses"}

Sin duda, el caudal de los recursos aportados por los diferentes medios acuáticos reunidos en la bahía de Gijón hubo de ser copioso. Las lagunas litorales propiciadas por las dunas, tal como veíamos más atrás, y la red de ríos, regatos y canales no dejarían de ofrecer la asequible fauna piscícola de aguas dulces, ambiente en el que además se podrían capturar anguilas y nutrias. Por lo que al borde costero se refiere, se hallaban al alcance áreas de condiciones bien contrastadas, desde esteros y prolongadas zonas de marisma, hasta intervalos de costa rocosa, alta y acantilada.

Una considerable extensión de marismas y marjales ocupaba el espacio sobre el que se fue extendiendo la ciudad de Gijón, seguida desde el estero desplegado en torno a la desembocadura del río Piles, con el arenal de San Lorenzo, hasta la marisma del Arbeyal, prolongada por el oeste hacia el espolón de Cabo Torres, a continuación del que, de nuevo, se abrían los bajíos inundados de la ría de Aboño. Es razonable que en la tradición mesolítica bien documentada al este del río Sella se complementara en la bahía gijonesa la recolección de moluscos, equinodermos y crustáceos, con la pesca variada, sin olvidar la captura de las aves acuáticas necesariamente abundantes 
en el paisaje ribereño del mar descrito. Poco habría que contraponer a la verosimilitud de una actividad pesquera intensa y rentable. Tanto los casos asturienses como otros de las cercanas costas atlánticas prueban el uso de anzuelos de hueso plenamente compatibles con otras artes de pesca como redes, horquillas, nasas y butrones, de empleo tan efectivo en las aguas fluviales como en las áreas intermareales. Es probable que la estructura costera, más allá de la bahía, el fuerte oleaje y las activas corrientes oceánicas no propiciaran experimentos náuticos de alguna envergadura y que la cercanía a la orilla de áreas profundas permitiera la captura ocasional de especies pelágicas sin necesidad de aventurarse mar adentro con los imprescindibles medios náuticos (Pickard y Bonsall, 2004). Pero la posibilidad del uso de embarcaciones para desplazamientos limitados no debería ser descartada cuando los logboats eran ya frecuentes en la Europa atlántica en el VI milenio a. C., existiendo otros tipos de embarcaciones en etapas anteriores a 9000 BP, de acuerdo con las fechas $\mathrm{C} 14$ de fragmentos de remos recuperados en yacimientos ingleses y alemanes (Lanting, 1997-1998).

Acaso la navegación de estuarios constituyera el medio, no exclusivo, para la captura de especies exóticas que sabemos que existieron en el Cantábrico entre 5200 y 4600 a. C. Nos referimos a algo tan llamativo como los restos del extinto Pinguinus impennis identificado en los yacimientos costeros vascos de Herriko Barra y Pico Ramos. Aportaba esta gran ave extinta a los groenlandeses prehistóricos su carne, huevos y grasa, esta última empleada también como combustible para las lámparas, y pieles para vestidos y otros fines (Meldgaard, 1988, citado en Zapata et al., 2007).

Como es bien sabido desde las investigaciones en la segunda década del s. Xx del conde de la Vega del Sella (1923), la huella instrumental asturiense, mesolítica, más precisa es el característico pico marisquero habitualmente asociado a los basureros -concheros- de los cazadores-recolectores asentados en la ribera marina, en especial la correspondiente al andén costero extendido entre las desembocaduras de los ríos Sella y Deva. Son ese tipo de picos, técnica, formal y dimensionalmente, simples destellos de la vida mesolítica en la costa central de Asturias, cuyo hallazgo se produce siempre en las inmediaciones del mar, tal como se precisa en la ría de Avilés, ensenadas de Bañugues y Luanco (Pérez, 1975; Pérez y González, 1996; Requejo et al., 2009) y Sobrepeña, sobre la ría de Villaviciosa (Martínez Villa et al., 1992), etc., hallazgos que dan solidez referencial a los picos en las orillas del río Piles (de Blas et al., 1978), en las inmediaciones de su desagüe en el mar en el límite oriental de la playa gijonesa de San Lorenzo (Fig. 3). El encuentro de algún pico asturiense en Tremañes -al sur de la mancha urbana de Gijón-, algo tierra adentro en la actualidad, no contradice su seguro vínculo con la explotación del medio litoral inmediato en los momentos de elevación del nivel de las aguas.

Pero ausentes las cuevas en un medio liotestratigráfico dominado por dolomías, calizas, margas, conglomerados, areniscas y lutitas -constitutivas de la cobertera mesozoico-terciaria de Gijón y su comarca-, los picos asturienses pueden poco más que denunciar la actividad marisquera y su correspondencia con las gentes de los milenios últimos de recolección y caza exclusivas. Acaso fueran también en ocasiones aquellos elementales instrumentos la huella equívoca de los neolíticos más tempranos que no tendrían que haber renunciado de forma radical a una fuente nutricia segura $y$ escasamente costosa en términos laborales.

Inciertos el momento y la forma de extinción del complejo asturiense (de Blas, 1987; Arias, 1997: 63-69, entre una ya cuantiosa bibliografía

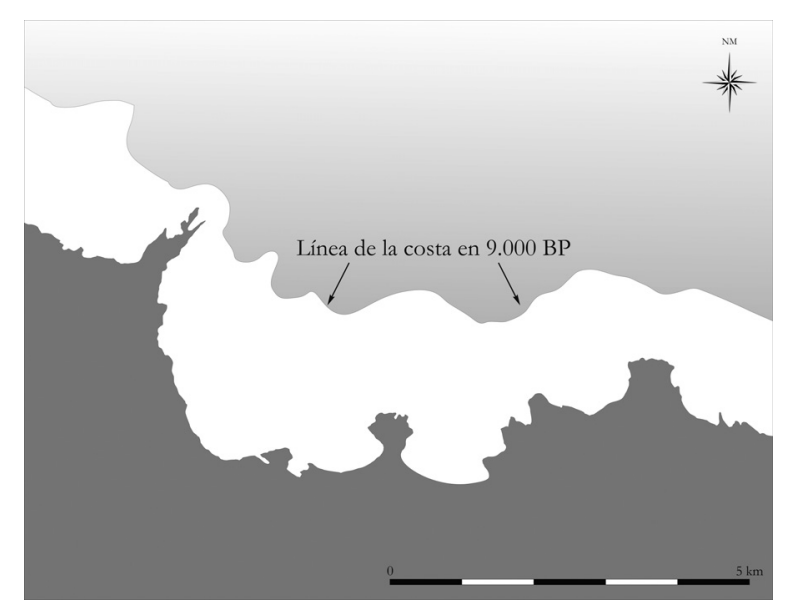

FIG. 3. Espacio comprendido (en blanco) entre la línea de costa actual y la existente c. 9000 BP (M. Á. de Blas y E. Martín Hernández). 
sobre este ciclo cultural), yacimientos cavernarios como los vizcaínos de Kobaederra y Pico Ramos o el cántabro de Los Gitanos documentan la actividad marisquera como complemento estimable de la subsistencia en los siglos primeros del $\mathrm{V}$ milenio a. C., sin que se perciba un nítido episodio de extinción de tales prácticas que probablemente tuvieran vigencia al menos hasta el fin de aquel milenio en la gruta de Santimamiñe (Gutiérrez Zugasti, 2009, en Fano, 2011). Además, la incidencia de la economía cinegética se manifiesta con especial acento en la explotación de los ciervos en la cueva, también costera, de Mazaculos, entre finales del V milenio y el primer tercio del IV a. C., si se acepta al límite el dilatado intervalo 42303630 cal BC derivado, además, de la sola fecha $5050 \pm 120$ вP (Marín y González, 2009).

El encuentro de los clásicos picos asturienses en áreas hoy afectadas por la acción de las mareas -desembocadura del Piles, ensenada de Bañugues, ría de Villaviciosa, etc.- y la menor altura del horizonte marino antes del 7000 BP (Fig. 4), tal

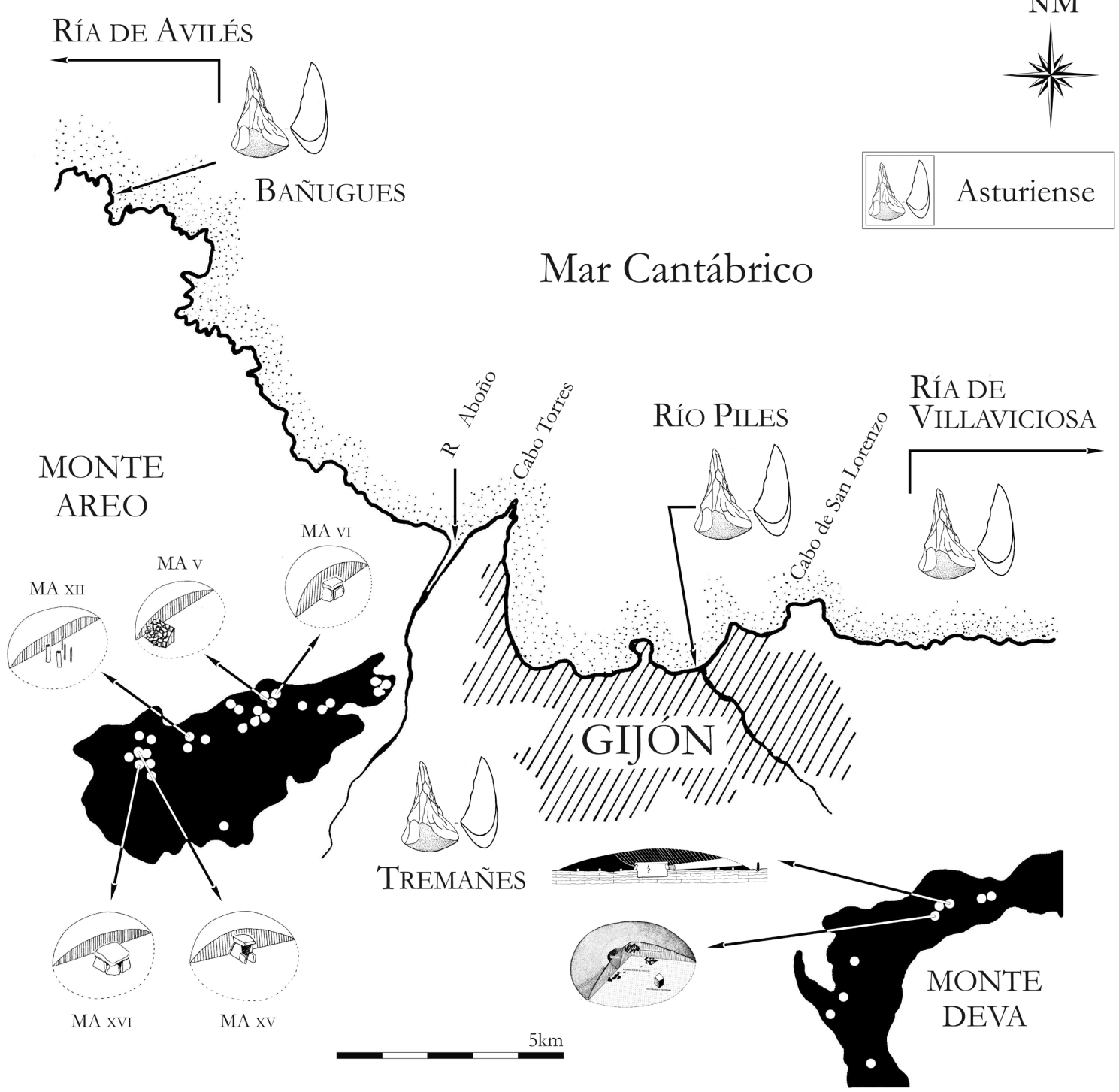

FIG. 4. Area del sector costero en torno a Gijón con las agrupaciones más importantes de túmulos y megalitos y puntos de localización de los picos "asturienses" mesoliticos (M. A. de Blas y E. Martín Hernández). 
como señalábamos, hacen verosímil la hipótesis de que algunos yacimientos litorales de los milenios VII y VI a. C. estuvieran situados en lugares hoy inaccesibles.

Hacia 9000 BP, en efecto, en el sector costero de Gijón discurría la orilla marina a 2 o $3 \mathrm{~km}$, como mínimo, de su límite actual, dejando disponible un amplio espacio para la acción humana más tarde anegado por las aguas, sumergiendo todo vestigio de aquella presencia. La ubicación de los picos asturienses que conocemos, hallados en las inmediaciones de la ribera oceánica, bien pudieran, como argumento plausible, pertenecer a la etapa tardía de los asturienses, marisqueando en el $\mathrm{V}$ milenio en un litoral muy cercano al actual.

La colecta de moluscos, en particular distintas especies de lapas, se produjo frecuentemente en zonas intermareales muy expuestas. La presión predadora en el Cantábrico durante el Mesolítico, pero también en época neolítica, sobre este molusco apreciado por su considerable aporte de carne, condujo al marisqueo en parajes que sólo serían accesibles en seco, por poco tiempo y en el transcurso de las mareas más vivas. Es por ello presumible que buena parte de los especializados picos de piedra empleados en el arranque de las lapas yazcan ahora en lugares sumergidos.

Valoradas las favorables condiciones fisiográficas y la disponibilidad de medios de sustento, no tendría sentido la ausencia humana en el territorio hasta el tiempo en que túmulos y megalitos vinieran a proclamar de forma contundente tanto su "colonización" por las primitivas comunidades agropecuarias, como la delimitación de los distintos ámbitos jurisdiccionales establecidos por las mismas.

El similar vacío humano que hoy se nos ofrece para el tardiglacial en la bahía tiene que ser igualmente irreal. Parece poco verosímil que las gentes de las sucesivas culturas del Paleolítico superior y las epipaleolíticas del Holoceno antiguo desdeñaran las amplias oportunidades materiales de la fecunda comarca costera. El sector litoral gijonés se une sin obstáculos con la Depresión central de Asturias bordeada por el sistema hidrográfico del río Nalón, en cuyo curso medio, al amparo de las abundantes cavernas, son numerosos y de rica información los yacimientos paleolíticos. A la relación entre estas poblaciones y el medio litoral, distante jornada y media de marcha, fue atribuida la presencia en los estratos magdalenienses de la cueva de Las Caldas, al suroeste de Oviedo, de restos de fauna marina; desde moluscos con o sin valor bromatológico -Nucella lapillus, Littorina obtusata y Pecten maximus - a mamíferos marinos testimoniados por algún diente de foca - Halichoerus grypus-, delfín -Globicephala melas- y cetáceo -Physeter macrodephalus/catodon-, materiales que habrían sido obtenidos en desplazamientos desde el Nalón a la ribera cantábrica (Corchón et al., 2008; Corchón y Álvarez, 2008). Tal vez resulte más plausible, no obstante, su recepción tierra adentro a través de los esperables intercambios con otros grupos; cadena de transferencia de bienes raros y apetecidos cuyo inicio deberíamos situar entre los residentes más habituales en la comarca marina.

En definitiva, la idea del desierto anteneolítico en la costa central de Asturias resulta, aun cuando carezcamos del esencial registro arqueológico, difícilmente digna de atención si, tal como se vino señalando, desde cualquier óptica que se aplique concurren en la comarca condiciones idóneas para la radicación humana.

Tampoco debiera ser una circunstancia cultural improbable que en el entorno de Gijón hubieran perdurado los modos de vida mesolíticos bastante después del 5000 a. C., siendo tal pervivencia compatible con la paulatina introducción de algunas novedades neolíticas que como la agricultura y ganadería eran ya realidad en el Cantábrico central y oriental a lo largo del aludido $\mathrm{V}$ milenio. La fecha $5890 \pm 80,5200-4690 \mathrm{cal} \mathrm{BC}$ para una tosca cerámica en la cueva de Los Canes -concejo de Cabrales-, en la Asturias oriental (Arias y Pérez, 1995), vendría a sustanciar la novedad de aquella artesanía alfarera como una probable inhábil creación local más que como un producto importado.

Otros testimonios, si bien limitados a fragmentos de mínimo tamaño y expresividad, se asocian ya a la nitidez neolítica del dolmen C de La Llaguna de Niévares, en los límites concejiles de Gijón con Villaviciosa (de Blas, 1999a), ya construido en el tercio inaugural del IV milenio. Hay que esperar todavía al intervalo 3900-3580 cal BC (UBAR-803; $4930 \pm 70 \mathrm{BP}$ ), correspondiente a la datación C14 de huesos de Bos taurus procedentes 
de una covacha en Llanera, al sur de Gijón -acaso provenientes de algún hábitat al aire libre-, para algunos vasos cerámicos de cierta calidad (Jordá Pardo et al., 2008), pero también para descubrir la existencia en la comarca de ganado vacuno, cuya previa aclimatación implica así mismo una mayor antigüedad en la zona.

\section{Megalitos y agricultura inicial en los márgenes de la bahía}

Una primera aproximación al paisaje botánico de Monte Areo durante su utilización inicial como orografía funeraria neolítica tuvo lugar en 1997 con la toma de muestras de sedimentos en los túmulos MA VI y MA XII para su estudio palinológico ${ }^{3}$. Cinco análisis del horizonte de base del megalito MA VI, sobre muestras obtenidas en las inmediaciones de la cámara ortostática, apuntaban al dominio de Corylus y una presencia notable de Quercus robur tp., además de Salix, esporas de Polypodium y pólenes de Poaceae y Cruciferae.

Fue bastante más explícita la información proporcionada por el túmulo MA XII, reflejando de nuevo el predominio forestal del avellano $(80 \%)$ frente al roble $(15 \%)$, siendo también identificados pólenes de Pynus sylvestris tp., abedul y aliso o sauce, especies detectadas en proporciones menores del 5\%. Fue hacia el final de aquella zona polínica donde se registrara la aparición de polen de cereal. Es probable que el llamativo protagonismo de Corylus tenga que ver con el incremento de la luminosidad ambiental favorecedor de su actividad polinizadora (Richard y Ruffaldi, 2004), síntoma entonces de un momento de bonanza climática, mientras que los pólenes de cereales, junto con los de poáceas, delaten la progresiva antropización del medio vegetal.

Considerando la posición de los vestigios de Cerealia, sitos ya en la masa del túmulo constitutivo del cuerpo del megalito -hacia los $0,75 \mathrm{~m}$ de

${ }^{3}$ Gómez-Orellana, R.; Ramil-Rego, P. e Iriarte Chiapuso, M. J. (2001): Resultados obtenidos a partir del análisis polinico del sedimento recogido en un dolmen (Monte Areo VI) y un túmulo (Monte Areo XII) emplazados en el entorno de Monte Areo (Asturias). Informe inédito elaborado en el Laboratorio de Botánica de la Facultad de Farmacia de Santiago de Compostela. la superficie actual del falso montículo-, bien se podría aceptar que provinieran sus pólenes del sedimento acopiado por los constructores de la edificación prehistórica, certificando, en tal caso, la realidad de prácticas agrícolas con anterioridad a la erección de la tumba monumental durante el último tercio del v milenio a. C. Tal opción no se contradice, sino todo lo contrario, con la naturaleza autógama de los cereales, cuyos pólenes apenas se dispersan por el viento, por lo que es muy escasa su distribución aleatoria (Bower, 1992).

Daría sentido esta última observación a la fecha radiométrica de algunos carbones vegetales recuperados en el sedimento integrante del horizonte sobre el que se levantó MA VI: GrN 19123: $5820 \pm 92$ BP; 4907-4463 cal BC. Esa orientación cronológica, hacia la primera mitad del $\mathrm{V}$ milenio, es plausible si se recuerda que en la cercana turbera aparecen en torno a $7300 \mathrm{cal} \mathrm{BP}$ -segunda mitad pues del VI milenio cal BC- los primeros indicadores antropogénicos. No nos resulta entonces desatinada la posibilidad de que los orígenes de la muestra carbonosa datada se deban a incendios relacionados en la misma zona con una acción deforestadora justificable, muy hipotéticamente, con la apertura de pastos para una ignota cabaña ganadera en el marco espacial gijonés. Tal pastoreo precoz se nos ofrece tanto más plausible cuando en yacimientos cavernarios de la mitad oriental del territorio cantábrico -en la gruta santanderina de El Mirón y en las vizcaínas de La Arenaza o Kobaederra- se documenta en el lapso 5100-4500 cal BC el ciclo inicial del disfrute de fauna doméstica, siendo grosso modo el mismo intervalo cronológico, 5200-4600 cal $\mathrm{BC}$, el que viera la aparición de la primera agricultura, con un retardo de algunos siglos con respecto a la misma innovación, 5600-5500 cal BC, en el litoral mediterráneo español (Zapata et al., 2004).

Conviene tener presente, sin embargo, que carbones de esa naturaleza y contexto pueden proceder tanto de causas naturales, particularmente relámpagos (Rowley y Conwy, 1981), como culturales, desde el fuego propagado involuntariamente partiendo de un hábitat, hasta los incendios provocados con fines cinegéticos (Edwards y Ralston, 1984). La incidencia de las quemas en época mesolítica fue atentamente 
considerada en distintas regiones, propiciadas tanto por actos venatorios como por la apertura de vistas hacia áreas de interés económico, cinegético, ocultas por la frondosidad forestal, conductas que permitirían suponer una menguada movilidad de los grupos humanos y su vínculo más estrecho con un territorio bien delimitado (Leroyer et al., 2004). En todo caso, el asunto plantea bastantes inseguridades ya que, entre otros, los factores tafonómicos relativos a las muestras carbonosas no son de fácil esclarecimiento. Aun así, todos los incendios intencionales se delatan tanto por su frecuencia y ubicación como por el hecho de que afecten a bosques compuestos por especies umbrófilas, poco inflamables (Beeching et al., 2004). Bajo tales presupuestos, la intensidad de los paleoincendios durante episodios mesolíticos avanzados y el primer Neolítico abogan por el protagonismo de la mano humana. Por lo que al área de Monte Areo se refiere, el arbolado dominante, sin ser necesariamente umbrófilo al estar compuesto por especies planocaducifolias (avellano, roble, abedul, aliso o sauce), ardería con cierta dificultad.

Centrándonos en el túmulo Monte Areo XII, la opción cultural, intencionada, resulta admisible, localizados los pólenes de Cerealia en compañía de especies ruderales, como $P$. lanceolata y $P$. persicae type, y de altos porcentajes de Erica.

Mucho más clarificadora es la información que pudo ser obtenida en la aludida ciénaga fósil de la Cañada del Reguerón, sita tan solo a algunos centenares de metros de los túmulos MA V y MA XII, en la que la evolución de pantano a turbera sería contemporánea de la primera agricultura hacia 6735-6495 cal BP, por tanto, entre 4700-4500 cal BC, una actividad "reanudada" con más continuidad en el intervalo 4300-3700 cal BC (LópezMerino et al., 2010).

Obviamente, llevar la agricultura inicial en el entorno de Gijón a la primera mitad del v milenio es coherente con la antigüedad de los cultivos más tempranos en la región cantábrica, datadas entre 5200 y $4700 \mathrm{cal} \mathrm{BC}$ muestras de polen y a partir de 4700 cal BC algunos macrorrestos de trigo y cebada (Zapata, 2007), mientras que los síntomas más precoces de tal actividad en tierras de Castilla ascenderían a mediados del VI milenio, de acuerdo con el registro de los niveles más antiguos de la cueva de La Vaquera, en Segovia (López García et al., 2003).

Bien es cierto que la información paleoagraria de Monte Areo es una fuente solitaria que no tolera generalizaciones; no obstante, en su propio espacio resulta congruente con la hipótesis de un primer tiempo de cultivos, tal vez discontinuos, $y$ otro posterior en el que agricultura y anotación territorial, la referencia jurisdiccional sustanciada en túmulos y megalitos, se convierten en testimonios firmes del definitivo asentamiento de la economía de producción y de los cambios materiales y mentales que aquella incorpora.

Para el primer episodio, 4700-4500, es aceptable la idea de una actividad circunstancial, acaso más relacionada con el deseo de prestigio que con una decidida vocación campesina. La domesticación como mecanismo de creación de alimentos de lujo, algunos tan novedosos o raros como los cereales, destinados a su consumo en festines y celebraciones motivados por la intención de notoriedad de un determinado grupo social, es ya una vieja propuesta (Bender, 1978; Hayden, 2003).

Así pues, el $\mathrm{V}$ milenio, y en particular su segunda mitad, se nos presenta como un tiempo crítico en el que la agricultura señala el atisbo del cambio Mesolítico-Neolítico, de sustitución paulatina del modelo cultural en un cúmulo discontinuo de contactos, influencias externas y experimentación de nuevas técnicas y de recepción de creencias e ideas, llegadas indistintamente por cauces diversos, el NO, la Meseta y el corredor litoral cantábrico. Es el momento de la novedad de los cultivos generadores de alimentos hasta entonces desconocidos o extrańos, probablemente prestigiados $y$, en todo caso, distintos de los derivados de la dieta transmilenaria de caza, recolección vegetal, pesca y marisqueo.

La edificación de túmulos y dólmenes fue realidad en la comarca de Gijón (Fig. 5) a partir del 4300/4000 a. C. -la época de los túmulos XII, V y VI de Monte Areo, y tal vez los A y D de la Llaguna de Niévares-, significando la definitiva radicación de las aportaciones económicas agropecuarias $y$, con ellas, una mayor dependencia de los ritmos laborales pautados por el ciclo vegetal. La creación monumental sustancia una forma de consumir los excedentes de producción, y el empeño 
84 Miguel Ángel de Blas Cortina / La implantación neolitica en la bahía de Gijón desde las postrimerías del V milenio a. C....

\begin{tabular}{|c|c|c|c|c|c|}
\hline Yacimiento & Material & Referencia Laboratorio & $\begin{array}{c}\text { Datación } \\
\text { BP }\end{array}$ & $\begin{array}{c}\text { Intersecciones/ } \\
\text { Edad a. C. }\end{array}$ & Intervalo $2 \delta$ \\
\hline La Llaguna A & Carbón & GrN-18282 & $5175 \pm 25$ & 4000 & $4060-3940$ \\
\hline La Llaguna A & Carbón & GrN-18283 & $5140 \pm 60$ & 3920 & $4100-3740$ \\
\hline La Llaguna D & Carbón & GrN-16647 & $5135 \pm 40$ & 3910 & $4070-3750$ \\
\hline La Llaguna D & Carbón & GrN-16648 & $5110 \pm 60$ & 3890 & $4050-3730$ \\
\hline Monte Areo XV & Carbón & GrN-19724 & $5070 \pm 70$ & 3840 & $4020-3660$ \\
\hline Monte Areo v & Carbón & GrN-22026 & $5470 \pm 90$ & 4300 & $4520-4080$ \\
\hline Monte Areo v & Carbón & GrN-22027 & $5330 \pm 50$ & 4320 & $4320-4000$ \\
\hline Monte Areo V & Carbón & UtC-9320 & $5239 \pm 43$ & 4080 & $4240-3920$ \\
\hline Monte Areo XII & Tronco de roble & UtC-7217 & $5368 \pm 44$ & 4200 & $4380-4020$ \\
\hline Monte Areo XII & Tronco de roble & UtC-7218 & $5404 \pm 41$ & 4270 & $4370-4170$ \\
\hline Monte Areo XII & Tronco de roble & UtC-7219 & $5368 \pm 42$ & 4210 & $4390-4030$ \\
\hline Monte Areo XII & Tronco de roble & UtC-7220 & $5284 \pm 42$ & 4130 & $4290-3970$ \\
\hline Monte Areo XII & Tronco de roble & CSIC-1378 & $5176 \pm 30$ & 4000 & $4060-3940$ \\
\hline Monte Areo XII & Tronco de roble & CSIC-1379 & $5261 \pm 31$ & 4100 & $4260-3940$ \\
\hline Monte Areo XII & Tronco de roble & CSIC-1380 & $5133 \pm 30$ & 3910 & $4050-3770$ \\
\hline
\end{tabular}

FIG. 5. Dataciones radiocarbónicas de algunos de los megalitos en el entorno serrano de la Bahía de Gijón (a partir de M. Á. de Blas, 1992, 1995a, 1995b, 1999b, 1999c, 2004 y 2006).

campesino, el modo de conseguirlos. Al mismo tiempo, la arquitectura monumental modifica la percepción del espacio y crea nuevas relaciones con el mismo, acontecimientos inseparables de un trasfondo sociopolítico, económico y mental (De Blas, 2004).

\section{La monumentalización neolítica en los límites serranos de la bahía de Gijón}

Monte Deva III (Fig. 6), en su ambición de monumentalidad con admisibles limitaciones en términos de disponibilidad de grandes lastras y
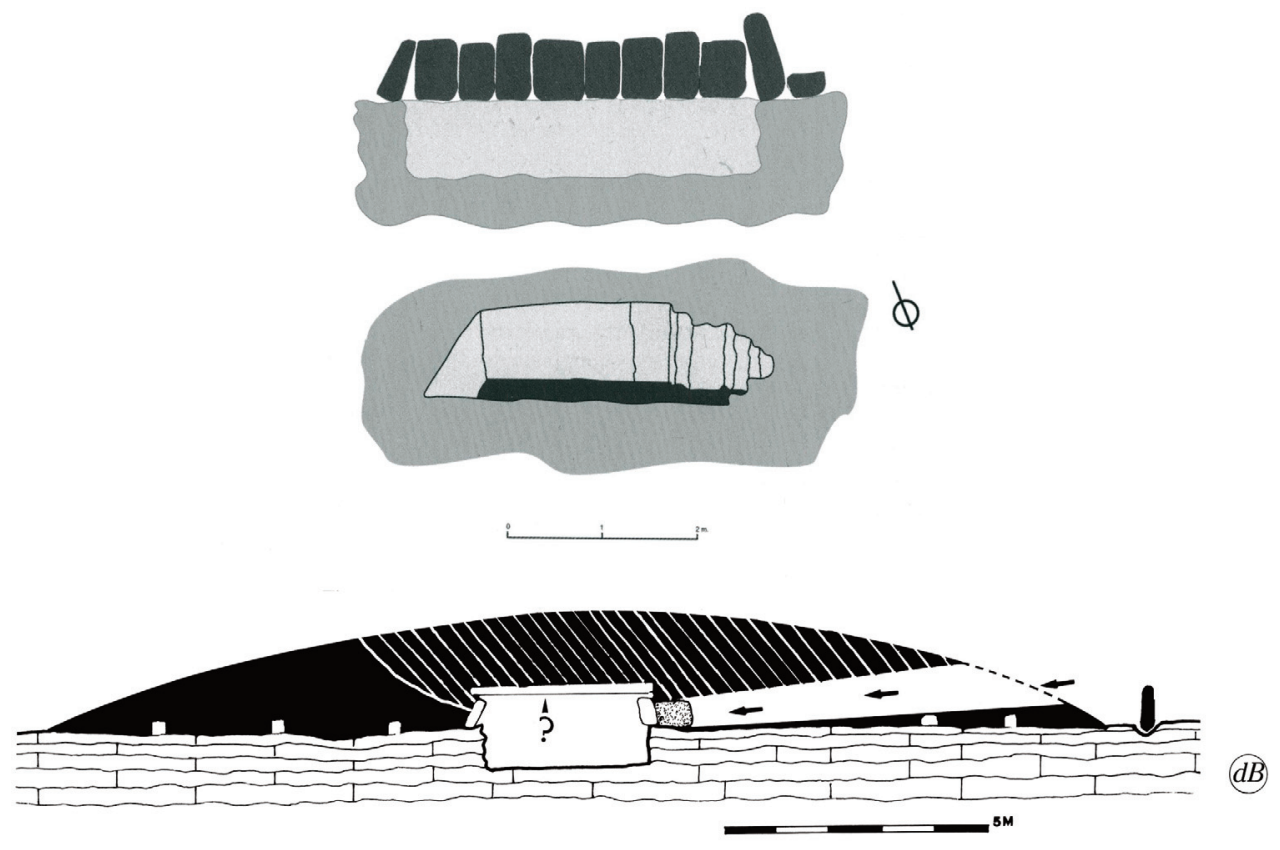

FIG. 6. Monte Deva III y su cámara excavada en la roca y completada con paredes ortostáticas. 
también de mano de obra cuantiosa, responde a la madurez del establecimiento neolítico en este sector central de la alargada región ribereña del Cantábrico. A esa plena adscripción dolménica corresponde el cercano dolmen $\mathrm{C}$, del conjunto de la Llaguna de Niévares, sito $8 \mathrm{~km}$ al $\mathrm{E}$ de Deva y en el mismo contexto de sierras litorales, megalito en el que su arquitectura ofrece una rara perfección, dotado de un primer túmulo envolvente de la cámara, edificado en forma hemiesférica mediante el encaje minucioso de los bloques pétreos que lo integran, precisándose además pistas muy elocuentes sobre las técnicas de cantería seguidas para la obtención de los ortostatos constitutivos del recinto sepulcral (De Blas, 1992, 1999).

Pero aún con mayor nitidez, en la baja sierra plana de Monte Areo, relieve que clausura la bahía gijonesa por poniente, algunos megalitos como Monte Areo VI, XV, XVI y XXII ilustran así mismo el episodio de mayor esplendor en la fase monumental megalítica (de Blas, 1995b, 1999b).
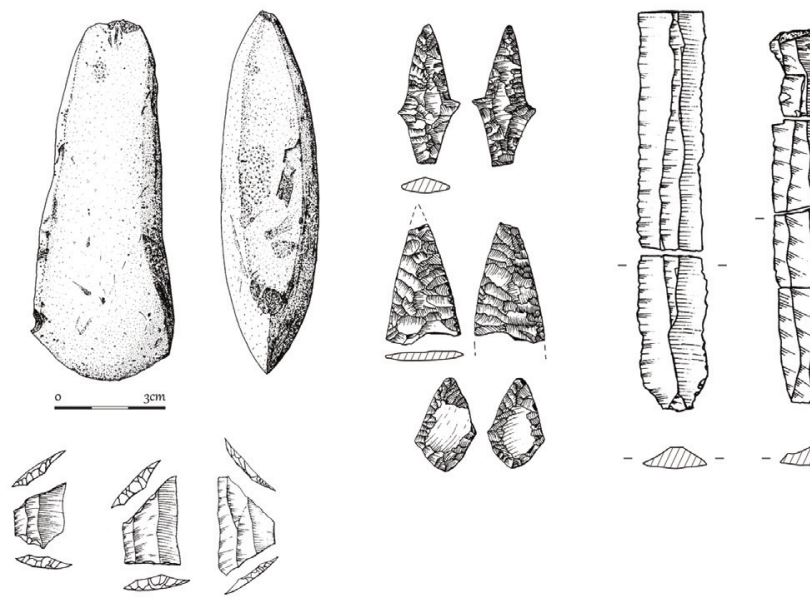

DRISTAL
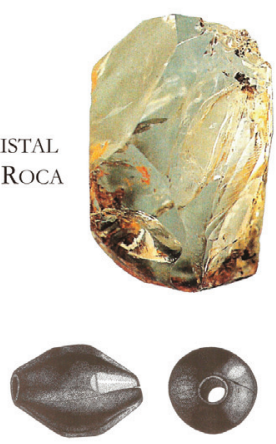

$-10$

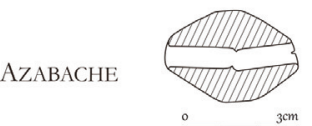

FIG. 7. Monte Areo $X V$ : megalito de cámara alta y pórtico $y$ los distintos tipos representativos del ajuar (C. M. López, L. Martinez Lorenz y M. Á. de Blas). 
86 Miguel Ángel de Blas Cortina / La implantación neolítica en la bahía de Gijón desde las postrimerías del V milenio a. C....

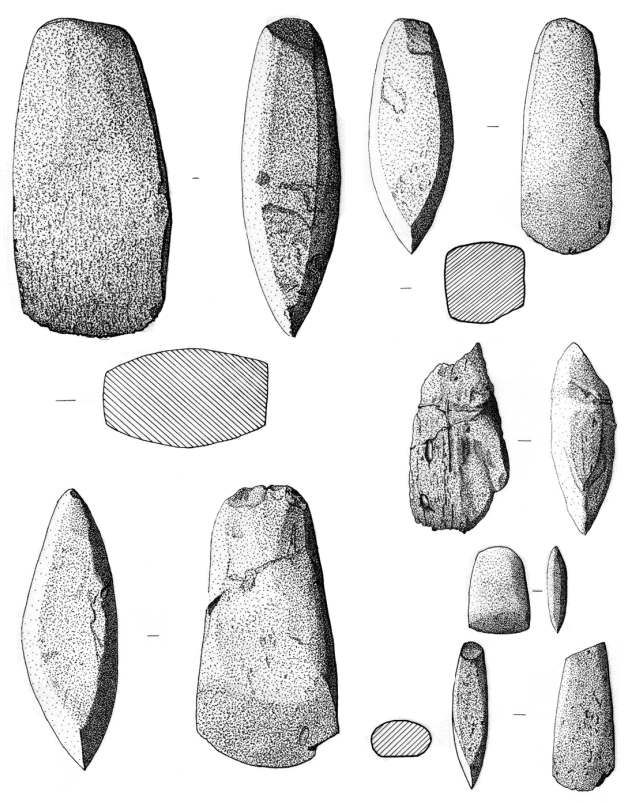

(P)

(A)
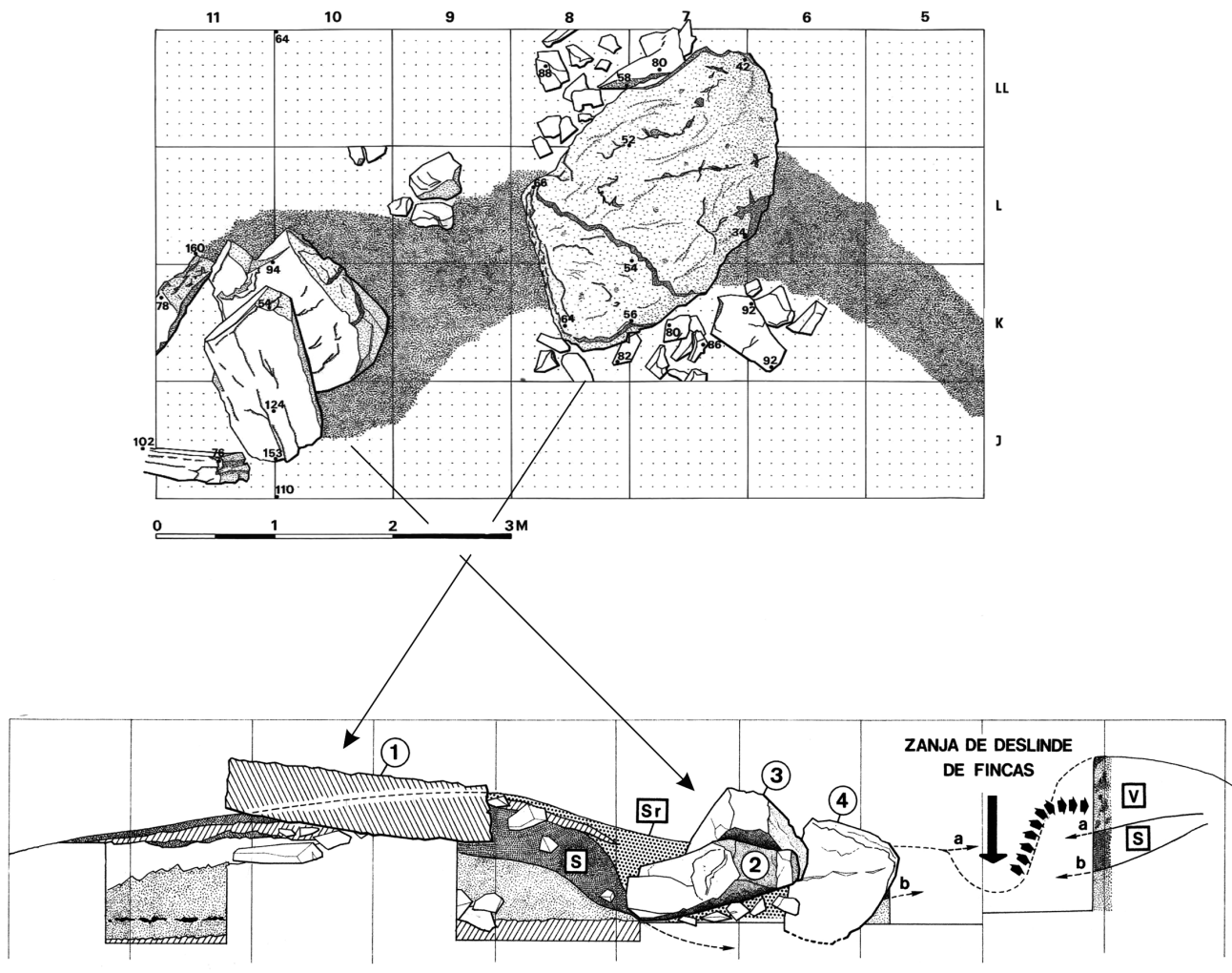

O $4 \mathrm{M}$

FIG. 8. Monte Areo XVI: planta, alzado y pulimentados procedentes de la cámara (C. M. López y L. Martínez Lorenzo). 
Monte Areo XV, con su cámara alta, pórtico de acceso lateral a la misma, y los viáticos mortuorios recuperados (Fig. 7), se enmarca en la fase megalítica de mayor expresividad en el NO ibérico, la ilustrada más acentuadamente por los dólmenes de corredor con pinturas y grabados parietales dentro de los recintos sepulcrales cuya realidad parece, sobre la datación radiocarbónica de las propias pinturas, incardinarse en la primera mitad del IV milenio a. C. (Carrera y Fábregas, 2001).

Tal como señalábamos más arriba, ese proceso de empeńo monumental tiene que ver, entre otros factores que lo determinan, con la disponibilidad de excedentes de producción difícilmente exportables a otros grupos sociales instalados en un modo similar de subsistencia. En cualquier caso, esa producción significa una considerable inversión laboral. El beneficio agropecuario del territorio requiere entre otros trabajos perentorios el desmonte de amplias parcelas enfrentándose a la exuberancia forestal, tareas que sólo restablecen el punto de partida de otras como la roturación del suelo, la siembra y subsiguiente vigilancia de los cultivos, recolección, tratamiento específico de la cosecha y labores inherentes a su almacenamiento; un conjunto de ocupaciones, dependencias y obligaciones que modulan la vida, desencadenando una lógica relación de proximidad con el suelo y su calidad. Es obvia, en ese tejido de actos y relaciones, la progresiva cristalización del sentimiento de propiedad de lo logrado y del medio en que fue obtenido; también entre posesión y poseedores. Recordemos que ya K. Marx (1965) observó, hace más de siglo y medio, que la propiedad de la tierra [en sociedades tribales] conduce a la conservación y a la reproducción,

en tanto que propietarios, de los individuos que componen la comunidad.

Así, de manera razonable, el catálogo de túmulos y megalitos erigidos en los límites serranos del tramo costero gijonés atestigua el peso de una población que no habría modo de explicar como inmigrante; la realidad de grupos ya empeñados en la demarcación del ámbito territorial que cada uno considera como propio.

Es evidente que los túmulos pautan el espacio a lo largo del IV milenio, deslindando marcos específicos de influencia grupal mediante los cementerios a los que se suele aludir como comunitarios, tratáranse de tumbas de destino restringido o de osarios colectivos.

En Monte Areo, la agricultura y la subsiguiente erección de las tumbas con túmulo vienen a documentar esa secuencia "explotación-posesión territorial" en un espacio muy preciso. Acaso elementos esenciales en tal proceso, las hachas y azuelas -empeñadas tanto en la deforestación,

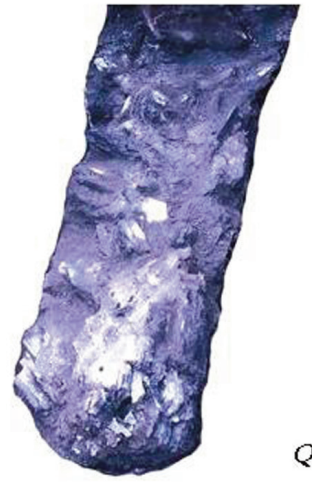

A
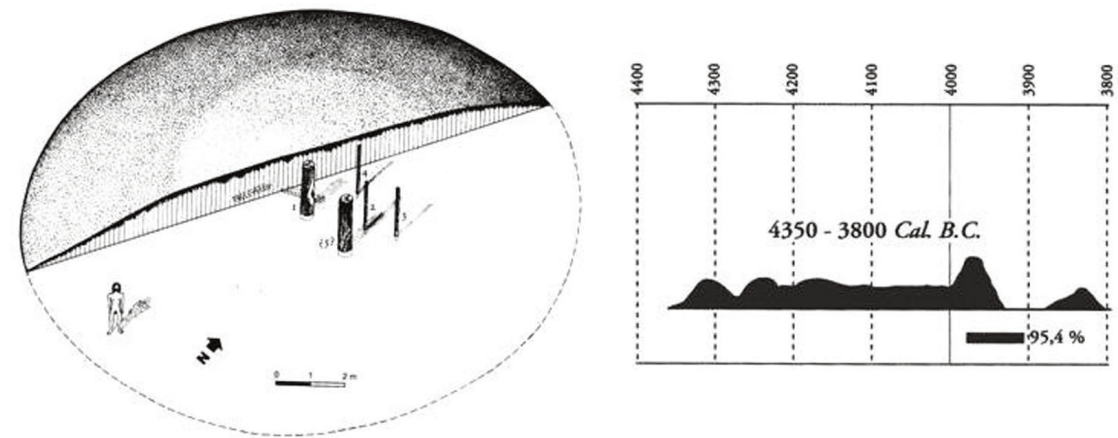

FIG. 9. Monte Areo XII: a) tronco y b) punta tallada, ambos de roble (M. Á. de Blas y L. Martínez Lorenzo). 
desmonte e incluso el labrado, como en la fabricación de cabañas y bienes diversos- pudieran estar conmemorando esa acción civilizadora a través del rito fúnebre. Las hojas pulimentadas recogidas en Monte Areo XVI (Fig. 8), en un ajuar en el que los demás constituyentes son numéricamente mínimos, bien pudieran en su naturaleza polisémica significar la alusión simbólica a esas conexiones entre subsistencia agropecuaria y la legitimación del dominio territorial; también al esfuerzo implicado en tales cometidos, presente en las melladuras y fracturas que delatan un empleo laboral previo a su destino en la ritualidad mortuoria.

No obstante, antes de la formalización de los túmulos adscritos a los tipos dolménicos clásicos ya se habían levantado túmulos de incierta estructura y función; arquitecturas muy sencillas que en algunos casos parecen haber significado la celebración de actos ceremoniales, entre otros los de sentido funerario, sobre suelos purificados, incontaminados y segregados del espacio natural. El recuerdo de esos lugares ideales requiere su protección y enmascaramiento mediante la edificación del montículo monumental, instalado en la ambivalencia ocultación de lo allí acontecido y denuncia del mismo hecho especial (de Blas, 2006). Es en ese ambiente primero en el que ubicar Monte Areo XII (Fig. 9) y su presumible cabanuuela de troncos de roble, destruida por el fuego antes de que todo quedara soterrado por el túmulo, y de Monte Areo V con su paramento pétreo,
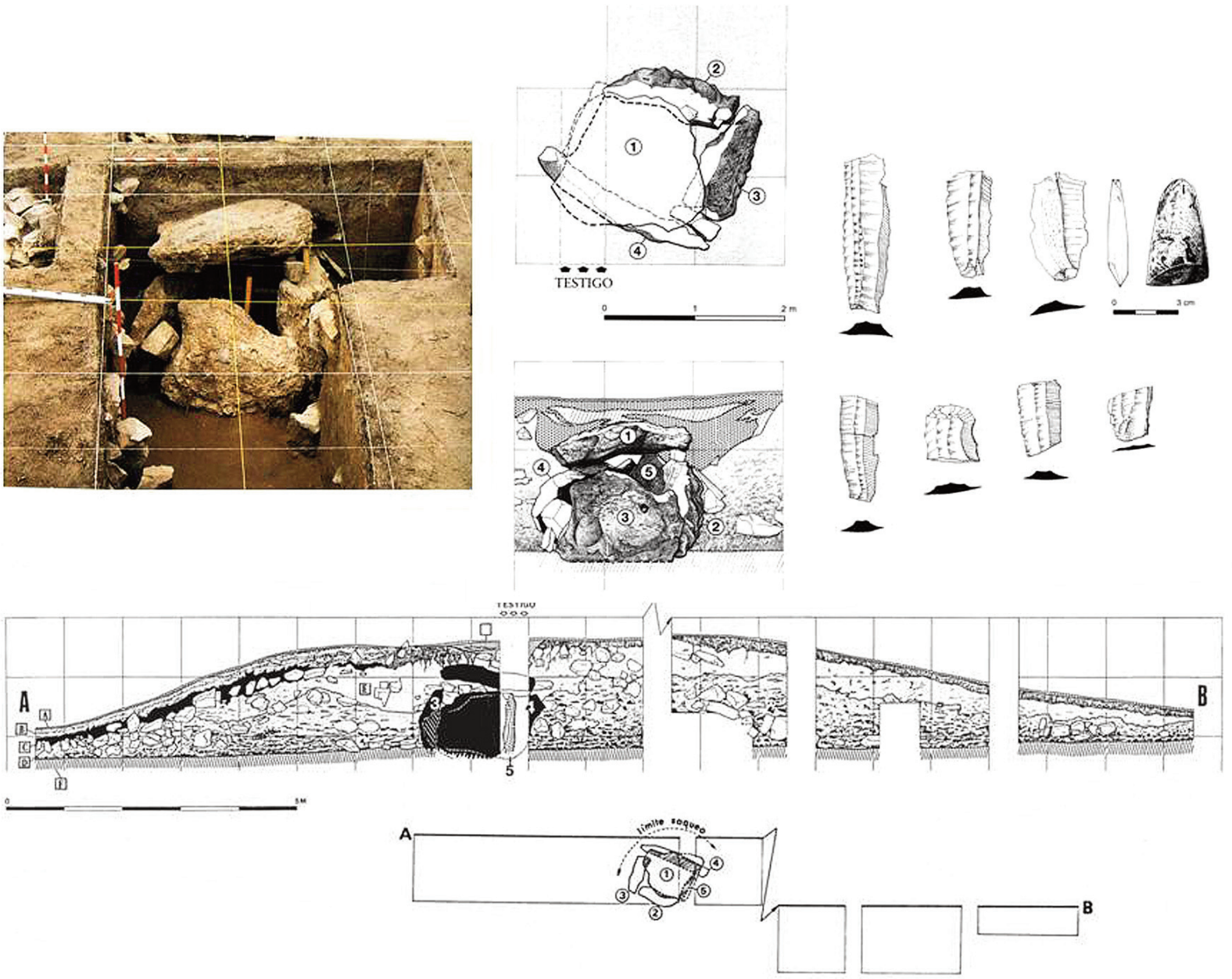

Fig. 10. Monte Areo VI: distintos detalles de la estructura megalítica y útiles asociados (C. M. López y M. Á. de Blas). 
poste de madera y gran hoguera asociada al mismo; túmulos erigidos durante el último tercio del v milenio a. C. Paralelamente, al oriente de la bahía, se levantaba la Llaguna A, en torno al 4000 a. C., túmulo en el que aún no se precisa una estricta cámara megalítica sino un espacio pavimentado y algún bloque esteliforme erguido. Poco después, grosso modo entre 4000 y 3700 a. C., la Llaguna D describe el pleno empeño monumental con un gran túmulo, protegido y realzado visualmente por una potente coraza pétrea, en cuyo interior, profunda e inaccesible fue erigida una camarita ortostática, probable relicario que anuncia las formas nítidamente dolménicas que ofrece en la misma época Monte Areo VI con su clara cámara-cofre soterrada por un potente túmulo (Fig. 10).

El crescendo monumental en la bahía gijonesa describe, en resumen, un ciclo que puede durar algo más de medio milenio, acaso entre 4300 y 3700 como segmento de referencia, secuencia secular que debería corresponderse con el juego de equilibrios sociales y de ajustes de la estructura territorial, consecuencia de la radicación definitiva, con los particularismos que se pudieran precisar, del modelo cultural neolítico.

\section{Recapitulación y notas finales}

De la heterogeneidad de los datos y perspectivas considerados podríamos resumir los cauces argumentales planteados en:

- Hacia 9000 BC discurría la orilla marina a la altura de Gijón a un mínimo de $2 / 3$ km de distancia de la ribera actual, abriéndose un amplio espacio litoral para la acción de los grupos mesolíticos cuyos tenues referentes arqueológicos, los típicos "picos asturienses", bien pudieran corresponder a la fase mesolítica tardía o, incluso, al ciclo inicial paleocampesino, cuando los marisqueadores del $\mathrm{V}$ milenio a. C. operaban sobre una costa muy próxima a la actual.

Hacia $7300 \mathrm{cal} \mathrm{BC}$, por tanto en la segunda mitad del VI milenio, se aprecian en un humedal de Monte Areo los primeros indicios antropogénicos, tal vez probables quemas promovidas por precoces prácticas pastoriles, sin olvidar que fuegos y ruderales pueden también corresponder a la acción de grupos mesolíticos vinculados a un territorio cada vez más reducido, con un modo de subsistencia de extremo aprovechamiento de los recursos naturales, lo que, a la larga, vendría a favorecer la adopción de la economía neolítica.

— Entre los milenios V y III a. C., en los siglos de arribada y asimilación de las pautas culturales paleoagrarias, la morfología de la bahía gijonesa no sería demasiado diferente de la de tiempos históricos. Hacia $5000 \mathrm{cal} \mathrm{BC,} \mathrm{y} \mathrm{después} \mathrm{de} \mathrm{un} \mathrm{largo}$ ciclo previo, el rico medio forestal dominado por robles y abedules, junto con el avellano y diversas "malas hierbas" comestibles y, con frecuencia, de alto valor nutritivo, aseguraba una esencial fuente de subsistencia a los pobladores de la confortable comarca litoral, subsistencia enriquecida con las amplias opciones de caza, en un medio de extensos bosques, y de la pesca tanto en aguas dulces como marinas, además de los rendimientos del marisqueo con distintas potencialidades y diversidad según se practicara en el litoral acantilado o en las áreas de estero, en los largos arenales playeros y en las lagunas determinadas por las formaciones de duna.

Serían las condiciones consideradas argumento básico para no confundir la endeblez del registro arqueológico con la ineludible realidad de la presencia humana durante milenios en la comarca gijonesa. A sólo una jornada de marcha hacia el sur, en la cuenca central transitada por el río Nalón, son tan abundantes como elocuentes los testimonios de la vida paleomesolítica; cuantiosas pruebas materiales cuya preservación se vio favorecida por la abundancia de las cavernas. La contradicción entre aquel espacio bien poblado y el desierto en la comarca litoral resulta demasiado chirriante como para otorgarle credibilidad. Tanto en la bahía de Gijón como en el ámbito litoral contiguo los sutiles vestigios mesolíticos "asturienses" deben ser pues valorados como el recuerdo de un poblamiento de tradición milenaria, banco genético constitutivo del capital humano en el que, durante el $\mathrm{V}$ milenio, tomarían cuerpo las novedades neolíticas.

- La seguridad de las prácticas agrícolas hacia 4700-4500 cal BC en el área de Gijón (de nuevo 
en el Humedal del Reguerón, en Monte Areo) descubre la recepción neolítica en su fase primaria, adaptativa, o subneolítica, expresión que ya utilizáramos en otras ocasiones (p. e. De Blas, 1997, 2000), una etapa en la que los primeros cultivos cerealísticos acaso tuvieran más que ver con el prestigio de sus impulsores (exhibición, por ejemplo, de un grupo ante otros de su dominio de nuevas técnicas) y con la conservación de su estatus que, estrictamente, con la mera subsistencia en una comarca de recursos continentales y marítimos de apreciada copiosidad.

- A partir de 4300-4200 a. C. se hará más sistemática la agricultura, al igual que los actos de certificación jurisdiccional sobre el territorio acreditados por la erección de túmulos de morfología diversa. La edificación de aquellos monumentos de estructura y ritualidad plurales, en algunos casos sobre los que entendemos como "suelos purificados", marca el inicio de un tiempo de exaltación monumental legitimadora de la propiedad territorial amparada en la continuidad generacional a partir de los antepasados: los ancestros con los que siempre se está en deuda (Testard, 2006: 81). Obviamente, sin desconocer que en la naturaleza plural de túmulos y megalitos se hallan también factores de peso como la exhibición de la potencialidad material de cada grupo y la contradicción de invertir en arquitecturas monumentales unos excedentes de producción que no podían ser intercambiados con gentes próximas, gestoras de un modelo económico semejante.

- La etapa primera de monumentalización se percibe, precisamente, en espacios de una primera utilidad agrícola como se constata en Monte Areo y en el caso particular de Monte Areo V, un temprano megalito de potente túmulo y discreta cámara en cofre, de estructura ortostática, modelo que habla más de tumba fundacional y exclusiva que de osario o sepulcro abierto a la prolongada recepción de cadáveres (de Blas, 1995b, 1999c). Es aún más evidente esa condición en La Llaguna D, donde un gran túmulo encierra, haciéndola inaccesible, una pequeña camarita que sólo cabe reconocer como un relicario (de Blas, 1992, 1995a). La Llaguna D surge en el umbral del IV milenio, fecha que también conviene a Monte
Areo VI. Pero el preludio de esa expresión monumental, al menos formalmente inteligible, conoció otros túmulos que calificamos más de una vez de enigmáticos representados firmemente por Monte Areo XII y Monte Areo V, erigidos en el tercio postrero del $\mathrm{V}$ milenio, siendo poco más tarde cuando La Llaguna A inaugurara uno de esos espacios funerarios, sacralizados, en las cumbres que miran tanto a los valles interiores como a la orilla marina.

El rápido incremento de la expresión monumental a partir de 4300/4200 a. C. delata la tensión in crescendo por la delimitación del área de control de cada grupo vinculado a los diferentes túmulos megalíticos; en otras palabras, la protección del suelo reconocido como propio, esencial económicamente y legitimado por los antecesores a quienes se atribuiría la relación favorable con los poderes que rigen la naturaleza y de los que depende la seguridad material.

- Avanzado el primer tercio del IV milenio se produjo la plena consolidación neolítica, percibida por la apuntada edificación de arquitecturas megalíticas clásicas, de mayor claridad funcional como los dólmenes de pórtico tipo Monte Areo XV o Monte Deva III, megalitos de cámara accesible, abierta mediante un pórtico, túnel o conducto, sin que nos atrevamos a imaginar entonces la cámara como un uterus en una asignación femenina de tales monumentos de ingreso lateral frente al carácter masculino de los túmulos encerrando cámaras aisladas (Gallay, 2006: 86).

Es por entonces cuando se registran las ofrendas más llamativas o valiosas que las amortizadas en los túmulos precedentes -Monte Areo XVI, La Llaguna C, y Monte Deva III (sílex importado, azabache, cuidadas puntas foliáceas de retoque plano, etc.)-; ajuares mortuorios que apuntan a las prerrogativas particulares de algunos inhumados. Tal vez fueran el sepulcro de linajes dominantes, capaces de estimular las relaciones de trueque con otros grupos, integrándose en cierta medida en las redes de circulación de productos alógenos de los que la huella visible suelen ser las materias pétreas de calidad o rareza, pero que implicarían mercancías más variadas y cuantiosas desde pieles de especies raras o escasas y panes de sal hasta algunas cabezas de ganado. 
Aun admitiendo en aquellas sociedades una moderada capacidad y bonanza económicas, el peso de los ritos mortuorios y su costosa materialización en las tumbas y en su mantenimiento son inteligibles, constatado etnográficamente el empeño monumental en contextos de franca escasez material (Huntington y Metcalf, 1979: 95). En todo caso, megalitos gijoneses como Monte Deva III apuntan a un poblamiento apenas nucleado, compuesto por grupos poco cuantiosos, congruentes en su discreta entidad con un hábitat disperso y de baja densidad demográfica, todo ello acorde con un territorio en el que el bosque ocupaba una gran proporción del suelo más idóneo para la gestión de la economía paleoagraria.

\section{Bibliografía}

ARIAS CABAL, P. (1997): Marisqueros y agricultores. Los orígenes del Neolítico en la fachada atlántica europea. Santander: Univ. de Cantabria.

Arias Cabal, P. y Pérez SuÁrez, C. (1995): "Excavaciones aerqueológicas en Arangas, Cabrales (19911994). Las cuevas de Los Canes, El Tíu Llines y Arangas". En Excavaciones Arqueológicas en Asturias 1991-94. Oviedo: Consejería de Cultura, pp. 79-92.

Alonso Millán, Á. y Pagés, J. L. (2010): "Evolución del nivel del mar en el Holoceno en el Noroeste de la Península Ibérica", Revista de la Real Sociedad Geológica de España, 23 (3-4), pp. 157-167.

BENDER, B. (1978): "Gatherer-hunter to farmer: a social perspective", World Arcaheology, 10, pp. 204-222.

http://dx.doi.org/10.1080/00438243.1978.9979731

Blas Cortina, M. Á. De (1987): "La ocupación megalítica en el borde costero cantábrico: el caso particular del sector asturiano". En El Megalitismo de la Peninsula Ibérica. Madrid: Ministerio de Cultura, pp. 127-141.

- (1992): "Arquitecturas megalíticas en la Llaguna de Niévares (Villaviciosa). Excavaciones de 1988 a 1990". En Excavaciones Arqueológicas en Asturias 1987-90. Oviedo: Consejería de Cultura, pp. 111-128.

- (1995a): "Destino y tiempo de los túmulos de estructura 'atípica': los monumentos A y D de la estación megalítica de la Llaguna de Niévares". En Primeros agricultores y ganaderos en el Cantábrico y Alto Ebro. Karratza 1993. Cuadernos de Prehistoria-Arqueología, 6, pp. 55-79.
- (1995b): "Dólmenes del Monte Areo, Carreño. Campañas arqueológicas de 1991 a 1994”. En Excavaciones Arqueológicas en Asturias 1991-94. Oviedo: Consejería de Cultura, pp. 93-104.

- (1997): "Megalitos en la región cantábrica: una visión de conjunto". En Rodríguez Casal, A. (ed.): O Neolítico Atlántico e as orixes do megalitismo. Coloquio Internacional (1996). Santiago de Compostela: Unión International des Sciences Préhistoriques et Protohistoriques-Univ. de Santiago de Compostela, pp. 311-334.

- (1999a): "Análisis e interpretación de una arquitectura prehistórica: el dolmen C de La Llaguna de Niévares, en Villaviciosa, Asturias". En De oriente a occidente. Homenaje al Dr. Emilio Olavarri. Bibliotheca Salmanticensis. Estudios, 205. Univ. Pontif. de Salamanca, pp. 161-184.

- (1999b): El Monte Areo, en Carreño (Asturias). Un territorio funerario de los milenios V a III a. C. Ayuntamiento de Carreño/Mancomunidad Cabo Peñas.

- (2000): "La neolitización del litoral cantábrico en su expresión más consolidada: la presencia de los primeros túmulos". En Actas do $3^{\circ}$ Congresso de Arqueología Peninsular. Vol. VIII. Neolitização e megalitismo da península Ibérica. Porto: Associaçao para o Desenvolvimiento da Coperação em Arqueología Peninsular, pp. 215-238.

- (2004): "Túmulos enigmáticos sin ofrendas: a propósito de Monte Deva V (Gijón) y Berducedo (Allande) en Asturias", Trabajos de Prehistoria, 61 (2), pp. 63-83.

- (2006): "La arquitectura como fin de un proceso: una revisión de la naturaleza de los túmulos prehistóricos sin cámaras convencionales en Asturias", Zephyrus, LIX, pp. 233-255.

- (2010): "Poder ancestral y territorio neolítico: en torno a Peńa Tú y los túmulos de la costa oriental de Asturias". En Fernández Eraso, F. J. y MújiCA, J. A. (eds.): Actas del Congreso Internacional sobre megalitismo y otras manifestaciones funerarias contemporáneas en su contexto social, económico y cultural. Munibe, Suplem. 32, pp. 94-118.

Blas, M. Á. De; González Morales, M. R.; MárQUez, C. y Rodríguez Asensio, J. A. (1978): "Picos asturienses de yacimientos al aire libre en Asturias", Boletín del Instituto de Estudios Asturianos, 93-94, pp. 335-356.

Bower, M. A. (1992): "Cereal pollen dispersal: a pilot study", Cambridge Archaeological Journal, 2, pp. 236-241.

http://dx.doi.org/10.1017/S0959774300000615

BRAUDEL, F. (1974): Cultura material y capitalismo. Barcelona: edit. Labor. 
BRothwell, D. (1986): The bogman and the archaeology of people. Massachusetts: Harvard University Press.

Carrera, F. y Fábregas, R. (2001): "Datación radiocarbónica de pinturas megalíticas del Noroeste Peninsular", Trabajos de Prehistoria, 59 (1), pp. 157-166.

http://dx.doi.org/10.3989/tp.2002.v59.i1.216

ClarK, J. G. D. (1978): Mesolithic Europe: the economic basis. London: Duckworth \& Co. Ltd.

Corchón, M. S. y Álvarez, E. (2008): "Nuevas evidencias de restos de mamíferos marinos en el Magdaleniense de la Cueva de Las Caldas (Asturias, España)", Munibe, 59, pp. 47-66.

Corchón, M. S.; Mateos, A.; Álvarez, E.; PeñalVer, E.; Delclós, X y MADE, J. VAN DER (2008): "Ressources complémentarires et mobilité dans le Magdalénien cantabrique. Nouvelles dones sur les mammífères marins, les crustacés, les mollusques et les roches organogènes de la Grotte de Las Caldas (Asturies, Espagne)", L'Anthropologie, 112, pp. 284-327.

http://dx.doi.org/10.1016/j.anthro.2008.02.008

Couplan, F. y STYNER, E. (2009): Guide des plantes sauvages comestibles et toxiques. Neuchatel: Delachaux \& Niestle.

Dimbleby, G. (1978): Plants and Archaeology. The Archaeology of the Soil. London: Granada Publishing Limited.

EdwardS, K. J. y Ralston, I. (1984): "Postglacial hunter-gatherers and vegetational history in Scotland", Proceedings of the Society of Antiquaires of Scotland, 114, pp. 15-34.

FAnO, M. Á. (2011): "Los primeros campesinos del Cantábrico: una revisión de la información disponible y de los modelos propuestos", Férvedes, 7, pp. 87-96.

Flor, G. y LHARTI, S. (2008): "Estratigrafía y sedimentología del recubrimiento costero de la ciudad de Gijón (Asturias)", Trabajos de Geología, 28, pp. 137-157.

Gallay, A. (2006): Les sociétés mégalithiques. Pouvoir des hommes, mémoire des morts. Lausanne: Presses Polytechniques et Universitaires Romandes.

García Antón, M.; Gil Romera, G.; Pagés, J. L. y Alonso Millán, A. (2006): "The Holocene pollen record in the Villaviciosa estuary (Asturias, North Spain)", Palaeogeography, Palaeoclimatology, Palaeoecology, 237, pp. 280-292.

http://dx.doi.org/10.1016/j.palaeo.2005.12.004

Guilaine, J. (2011): Caïn, Abel, Ötzi. L'héritage néolithique. Paris: édit. Gallimard.
Gutiérrez Claverol, M.; Torres, M. y LuQue, C. (2002): El subsuelo de Gijón. Aspectos geológicos. Oviedo: CQ Licer.

GutiÉRrez Zugasti, F. I. (2009): La explotación de moluscos y otros recursos litorales en la región cantábrica durante el Pleistoceno Final y el Holoceno inicial. Santander: Univ. de Cantabria.

Hayden, B. (2003): "Were luxury foods the first domesticates? Ethnoarchaeological perspectives from Southeast Asia”, World Archaeology, 34 (3), pp. 458-469.

http://dx.doi.org/10.1080/0043824021000026459a

HelbaeK, H. (1980): "Paleo-etnobotánica". En Brothwell, D. y HigGs, E. (comps.): Ciencia en Arqueología. México: Fondo de Cultura Económica, pp. 209-218.

Holden, T. G. (2001): "Dietary Evidence from the Coprolites and Intestinal Contents of Ancient Humans". En Brothwell, D. R. y Pollard, A. M. (eds.): Handbook of Archaeological Sciences. London: John Wiley \& Sons Ltd, pp. 403-413.

Huntington, R. y Metcalf, P. (1979): Celebrations of Death. Cambridge: Cambridge University Press.

Jordá, J.; Estrada, R.; Mestres, J. S.; Yravedra, J. y MaRín, C. (2008): “Un asentamiento neolítico de superficie en el interior de una cueva: Torca l'Arroyu (Llanera, Asturias)". En Actas IV Congreso del Neolitico peninsular. Alicante: Diput. Provincial, t. 1, pp. 208-215.

Lanting, J. N. (1997-1998): "Dates for origin and diffusion of the European logboat", Palaeohistoria, 39-40, pp. 627-650.

Leroyer, Ch.; Mordant, D. y Lanchon, Y. (2004): "L'anthropisation du Basssin parisien du VIIe au IVe millénaire d'aprés les analyses polliniques de fonds de vallées: mise en évidence d' activités agro-pastorales très précoces". En Richard, H. (dir.): Néolithisation précoce. Prémiers traces d'anthropisation du couvert vegetal à partir des données polliniques. Besançon: Presses Universitaires de Franche-Comté, pp. 11-27.

López García, P.; Arnanz, A. M.; Macías, R.; Uzquiano, P. y Gil Hernández, P. (2003): "Arqueobotánica de la Cueva de la Vaquera". En Estremera, M. S. (ed.): Primeros agricultores y ganaderos en la Meseta Norte: El Neolítico de la Cueva de La Vaquera (Torreiglesias, Segovia). Arqueología en Castilla y León, 11. Memorias. Valladolid, pp. 247-256.

López Merino, L.; Martínez Cortizas, A. y LópezSÁEZ, J. A. (2010): "Early agriculture and paleoenvironmental history in the North of the Iberian Peninsula: a multi-proxy análisis of the Monte 
Areo mire (Asturias, Spain)", Journal of Archaeological Science, 37, pp. 1978-1988. http://dx.doi.org/10.1016/j.jas.2010.03.003

Marín, A. B. y González Morales, M. R. (2009): "Comportamiento económico de los últimos cazadores-recolectores y primeras evidencias de domesticación en el occidente [sic] de Asturias. La cueva de Mazaculos II", Trabajos de Prehistoria, 66 (1), pp. 47-74. http://dx.doi.org/10.3989/tp.2009.09012

Martínez Villa, A.; Requejo, O.; Cabo, C. y JiméNEZ, M. (1992): "Las cartas arqueológicas de Gijón y Villaviciosa. Métodos y resultados". En Excavaciones Arqueológicas en Asturias 1987-90. Oviedo: Consejería de Cultura, pp. 238-245.

MarX, K. (1965): Oeuvres. Économie, I. Paris: édit. Gallimard.

PÉreZ, M. (1975): "Los yacimientos prehistóricos de la región de Cabo Peñas". En XIII Congreso Nacional de Arqueología. Zaragoza, pp. 109-118.

PÉreZ, M. y GONZÁleZ, L. (1996): "Nuevo yacimiento paleomesolítico de Aramar, Luanco (Gozón, Asturias) y sus aspectos geológicos", Veleia, 13, pp. 7-70.

PicKARD, C. y BONSALL, C. (2004): "Deep-sea fishing in the European Mesolithic: fact or fantasy?, European Journal of Archaeology, 7 (3), pp. 273-290. http://dx.doi.org/10.1177/1461957104056504

Ramil, P.; Muñoz-Sobrino, C.; Rodríguez GuiTIÁN, M. y GÓMEZ OrELlANA, L. (1998): "Differences in the vegetation of the North Iberian Peninsula during the last 16.000 years", Plant Eco$\log y, 138$, pp. 41-62. http://dx.doi.org/10.1023/A:1009736432739

Requejo, O.; Calleja, S. y Martos, E. (2009): "Seguimiento arqueológico de la construcción de la AS-239: nueva carretera Candás-Luanco". En Excavaciones Arqueológicas en Asturias 2003-2006. Oviedo: Consejería de Cultura y Turismo, pp. 527-533.

Richard, H. y RufFaldi, P. (2004): "Premières traces polliniques d'influence de l'homme sur la couvert vegetal de l'Est de la France". En Richard, H. (dir.): Neolithisation précoce. Premières traces d'anthropisation du couvert végétal à partir des données polliniques. Besançon: Presses Universitaires Franccomtoisses, pp. 117-125.

ROWLEY-CONWY, P. (1981): "Slash and burn in the Temperate European Neolithic". En Mercer, R. J. (ed.): Farming Practice in British Prehistory. Edinburhg: University Press, pp. 211-221.

- (1986): "Between cave painters and crop planters: aspects of the temperate European Mesolithic". En Zvelebil, M. (ed.): Hunters in transition. Mesolithic societies of temperate Eurasia and their transition to farming. New Directions in Archaoelogy. Cambridge: Cambridge University Press, pp. 17-32.

Tardío, J.; Pascual, H. y Morales, R. (2002): Alimentos silvestres de Madrid. Guia de las plantas y setas de uso alimentario tradicional en la Comunidad de Madrid. Madrid: Jardín Botánico y CSIC, Comunidad de Madrid y Consejería de Educación e Innovación Tecnológica.

Testard, A. (2006): Des dons et des dieux. Anthropologie religieuse et sociologie comparative. Paris: èdit. Érrance.

Vega del Sella, CONDE De la (1923): El asturiense. Nueva industria preneolítica. Madrid: Comisión de Investigaciones Paleontológicas y Prehistóricas.

ZapATA, L. (2007): "First farmers along the coast of the Bay of Biscay". En Colleage, S. y Conolly, J. (eds.): The Origins and Spread of Domestic Plants in Southwest Asia and Europe. California: Left Coast Press, pp. 189-208.

Zapata, L.; Milner, N. y Roselló, E. (2007): "Pico Ramos cave shell midden: the Mesolithic-Neolithic transition in the Bay of Biscay". En Milner, N.; Craig, O. E. y Bailey, G. N. (eds.): Shell middens in Atlantic Europe. Oxford: Oxbow Books, pp. 28-36.

Zapata, L.; Peña-Chocarro, L.; Pérez-Jordá, G. y STIKA, H.-P. (2004): "Early Neolithic agricultura in the Iberian Peninsula", Journal of World Prehistory, 18 , n. ${ }^{\circ}$, pp. $283-235$. 